\title{
OBSERVATIONS AND EXPERIMENTS ON THE CASE-BUILDING INSTINCT OF TWO SPECIES OF TRICHOPTERA
}

\author{
By Manton Copeland and Sears Crowell \\ Searles Biological Laboratory, Bowdoin College, \\ Brunswick, Maine
}

The observations recorded here concern the case-building activities of two species of caddis fly larvæ. The first of these belongs to the Limnephilidæ, the other is a species of Molanna. Our interest in studying the case-building of these animals has centered around the experimental modification of the process, and we have endeavored to determine the extent to which this instinctive activity may be altered or adapted to changed conditions. Dembowski (1933) has made a very careful study of the case-building of Molanna, regarding this process as significant in indicating the plasticity of an animal's actions. Many papers on the casebuilding of caddis flies are to be found, but no others with this viewpoint. (See bibliography of Betten, Lloyd, or Greene and Milne.) Although our experimental work awaits completion, it has seemed proper to publish those observations which are believed to be new and which may be of assistance to others who are studying animal behavior or the natural history of the Trichoptera. ${ }^{1}$ The various materials which these animals are able to use in the construction of the cases are described, as well as a few experiments in which there was an opportunity for the animals to use more than one kind of material, or to select the more appropriate one. The early steps in the formation of the cases are described in some detail. We believe no complete account of these has been published for any caddis fly larva except Molanna. This is unfortunate since this part of the process is the most difficult, and we have observed a greater differ-

\footnotetext{
${ }^{1}$ Since 1933 several authors have published comprehensive papers on Trichoptera as shown in the bibliography. In fact it was largely through the interest of one of these, Mr. Milne, that we undertook the publication of these observations made by us in 1930 .
} 
ence in the method of procedure of different species at this stage than at any other.

The limnephilid which we studied builds a case of the "log cabin" type, that is of small pieces of plant material placed transversely with respect to the long axis of the case. In studying the animals it was customary to push them out of their cases with a blunt needle and place them in a small dish with water and materials with which they might build a case. All of the materials mentioned in the accounts which follow which would not usually sink in water (e.g. paper and pine needles) were kept in it until they became waterlogged before being used.

The typical case-building procedure as observed in the laboratory is as follows. A larva, pushed from its case, is placed in a dish containing plant debris similar to that ordinarily used in its case. It crawls about for a time, then commences to gather bits of plant material beneath itself, holding them partly with its legs and partly by curling its abdomen downward. Soon, by employing a salivary secretion, it joins to one another the plant fragments that have been collected. In this way an irregular chain is formed composed of the pieces of building material. When the chain is of sufficient length the larva holds one end of it with the legs of one side and with a leg of the other side reaches around in back of itself for the free end of the chain. This is then drawn around to the ventral side and the two ends joined. The procedure is similar to that followed by a person in putting on a belt: he holds one end in front of himself and with his other hand reaches around in back for the free end which is then brought forward and fastened. In his account of the case-building of a caddis-worm, Limnephilus flavicornis, Gorter refers to this wrapping of the girdle around the larva in forming a "provisional case". He does not, however, describe the procedure.

The girdle formed of the chain of loosely-joined pieces constitutes the foundation on which the first part of the case proper is built. This girdle is held by the larva at the level of the metathorax and pieces of plant material are added, one at a time, to the forward edge.

The method of building the case from this point on has been described by others (See Lloyd 1921, Gorter 1929), and 
we have no new observations on this part of the process. Each piece of plant material is taken by the larva, smeared with the salivary secretion and set in place. As the case is extended, the original girdle and the completed part of the case are moved backward so that they cover the abdomen. The end to which new material is being added stays in the same position where it is easily reached by mouth-parts and legs. By the addition of material at the forward end the case is eventually completed.

Observations were also made on case-building in Molanna. Using sand grains these larvae build cases consisting of a central cylindrical tube, having at the anterior end a broad extension or overhanging hood that protects the animal from above even when its head and thorax are projected from the tube proper. This broad hood extends backward on either side of the main part of the case and forms lateral flanges possibly useful in preventing the case from rolling on its side.

The typical case-building procedure of a Molanna larva when pushed from its case and supplied with sand to the depth of about a centimeter is as follows. For about a minute the larva crawls about over the sand. It then curls its abdomen downward so that it no longer moves forward even though it continues to move its legs. This results in the digging of a slight pit in front of the larva and in the formation of a pile of sand beneath the body. Presently the head is forced down into the pit and turned underneath the pile of sand and underneath the body of the larva. Thus the animal is curled and lies on the back of its head as in the first step of a somersault. It then digs farther into the sand, joining the sand grains together loosely with the salivary secretion. Its head finally emerges at the surface on the side of the small pile of sand where the abdomen was located when the process began. The larva at this point has nearly completed a somersault and lies on its back in a sort of tunnel beneath the pile of sand. It next joins together the sand grains around the opening of the tunnel. When the sand grains which line the entrance to the tunnel have been firmly cemented together the animal is encircled by a firm girdle. As in the limnephilid, this is the foundation to which further building material is added to effect the completion of the case. In Molanna the girdle may be completed within fifteen 
minutes. It is clear that the formation of the girdle, the initial and most difficult step in case-building, is accomplished here by a quite different method than in the limnephilid.

The larva remains partly buried in the sand and by adding sand grains to the anterior edge of the girdle extends it to form a tube. This is similar to the method employed by the limnephilid in completing its case.

The hood which overhangs the anterior opening of the tube is constructed as soon as the latter is finished, but its backward extensions (flanges) on either side of the tube may not be completed for one or two days.

On several occasions a larva of Molanna was put into a dish with only a small amount of sand, that is with an amount insufficient to permit the burrowing and tunnel formation as described above. Under these circumstances the larva forms the girdle in a somewhat different manner, as follows: The larva collects sand grains into a small pile beneath itself. These are then joined loosely together by the salivary secretion. The larva then thrusts its head into this loosely aggregated mass of sand. If the sand holds together on all sides the larva thus surrounds itself with a girdle. Often the mass of sand breaks apart as the larva burrows into it. When this occurs the procedure is repeated. ${ }^{1}$

From this it appears that a Molanna larva, when there is only a small amount of sand, forms the girdle by burrowing, even though this is difficult and often unsuccessful. Since no attempt is made to form a girdle by wrapping the aggregated sand grains around itself, the method is not like that employed by the limnephilid, a procedure which might be more effective than the one actually used. It seemed to us that this method of girdle formation very closely resembled that employed by Molanna in deep sand, the only difference consisting in the cementing together of some sand grains before burrowing commenced.

It is well known that caddis-fly larvae are able to employ unusual materials in the construction of cases. We found that the limnephilid larvae were able to build cases of small

\footnotetext{
${ }^{1}$ Dembowski (1933) reports one case in which a larva of Molanna, receiving an insufficient supply of building material, burrowed between the pile of material and the glass bottom of the dish, ultimately using the dish as the under side of its case.
} 
bits of pine needle (Pinus Strobus), or in part of paper. The Molanna larvæ built cases of assorted debris when no sand was present; they built cases of both sand and plant bits when both were present; and were also able to make a case composed only of small pieces of broken glass.

The method of construction and the form of the case in all observed instances depends on the species rather than on the type or scarcity of material employed. Our observations lead us to regard the modification in the behavior of a larva when supplied with insufficient or unusual material as rather slight. The animal adheres as closely as possible to its usual method of case-building.

Dembowski, who studied only one species (Molanna, though probably not the same species as that used by us), emphasizes the variability and plasticity of the animals' activities under varied circumstances. Comparison of the behavior of various species, especially during the early steps of case-building when the larvæ work rapidly, leads us to regard the variations within each species as slight and of little significance.

A few tests were made with limnephilid larvæ to determine whether they would select short pieces of pine needles rather than longer ones which would require cutting by the larvae if they were to be used at all. In one test a larva with a case partly completed was given 50 bits of pine needle $3.5 \mathrm{~mm}$. in length (about the length normally used) and 30 bits $11 \mathrm{~mm}$. in length (a length greater than that of any of the pieces in any observed case built by larvae of this species). A few days later there were only 19 short bits left in the dish though 25 of the longer ones remained. The larva had certainly discarded the long pieces except in a very few instances. Since there were no long pieces in the case it is clear that the animal must have cut up the missing 5 long pieces. In a similar experiment performed later on the same animal 3 out of 25 short pieces were unused and 14 out of 15 long pieces were unused, that is, with but one exception, only the short pieces were accepted.

If a larva which has no case at all is given $11 \mathrm{~mm}$. bits of pine needle it joins the pieces and forms a girdle but the structure is too cumbersome and inflexible to permit its being wrapped around the animal. The larva will again and again make the motions of wrapping the chain about itself, and 
failing will make another chain, or add to the same one and then again "endeavor" to complete a girdle. It does not, however, cut the pieces to a length which would permit their effective use. With $3.5 \mathrm{~mm}$. bits a girdle may be completed. Larvae supplied with a mixture of long and short pieces use both to make the chain of material that precedes the formation of the girdle, but because this contains some long ones they are unable to wrap it around themselves to complete it. We found no evidence of a selection of material during the early steps in case formation when the length of the pine needle fragments was the only varying factor. Gorter (1929, p. 92) in the limnephilid that he studied observed that: "In the construction of the provisional tube all kinds of material were employed by the larvae, but the pieces could not be too large, for the larva did not bite the material into smaller pieces during the provisional building-process. Biting takes time and during the provisional building-process the larva makes the impression of being in a great hurry. Speed is the chief thing, not firmness, as with the final structure...."

These observations clearly indicate that during girdle formation there is little or no selection and no cutting of materials, but that later when the case is partly completed there is both selection and cutting. However, if the choice during the early steps lay between flexible and stiff material the animals might have shown some selection, for Gorter (p. 92) observes: "In the provisional building-process one thing was very remarkable: there was a great preference for algae, a flexible and soft material, which can be quickly wrapped around the larva without being bitten off." We have not tested this point.

No thorough tests were made to determine whether Molanna would show selection of building materials during the early stages when it works rapidly. However, as the case nears completion and the animal works more slowly there is evidence of selection.

Examination of cases of Molanna shows that the sand grains of the tube are more varied in size than those of the flange and hood. The latter are nearly all relatively large grains. In one instance in which a larva had been supplied with a mixture of glass and sand the result was a completed case almost all of sand but with some glass in the older part 
of it. In another instance a larva was supplied with plant bits only. Using these it formed a case, complete except for the flanges on the sides. The animal remained in the dish with plant bits for two days. No pieces of material were added during the second day. On the third the larva in its case was put into a dish containing sand. It at once began to add sand grains at the anterior end, at first on the hood, then at the edge of the tube proper. By the next day quite a good deal of sand had been added at the anterior end though the main part of the case was of the plant bits. Further investigation, however, is needed to indicate clearly the extent to which Molanna selects appropriate materials at different stages in the process of case-building.

\section{SUMMARY}

1. The first steps in case-building, i.e., the formation of a girdle, are described both for a limnephilid and for Molanna. The method is quite different in the two species.

2. Both the limnephilid and Molanna are able to employ a variety of unusual materials in the construction of their cases.

3. Even when supplied with insufficient or unusual materials, these caddis fly larvae build cases in close accordance with the method characteristic of the species.

4. In the limnephilid there is little evidence that the animals select the more appropriate lengths of materials during early steps of case construction. As the case nears completion, however, considerable selection does occur. Incomplete evidence is presented of a similar situation in Molanna.

\section{BIBLIOGRAPHY}

Betten, C. 1934. The Caddis Flies or Trichoptera of New York State. New York State Museum Bulletin. No. 292, pp. 1-576.

Dembowski, Jan. 1933. Über die Plastizität der tierischen Handlungen. Beobachtungen und Versuche an Molanna-Larven. Zool. Jahrb. Abt. allg. Zool. u. Physiol., vol. 53, pp. 261-311.

Gorter, F. 1929. Experiments on the case-building of a caddis-worm (Limnophilus flavicornis Fabr.) Tydschrift der Nederlandsche Dierkun dige Vereeniging. (3) vol. 1, pp. 90-93.

Greene, M. J. and L. J. Milne, in press. Immature North American Caddis Flies (Trichoptera). 1. A summary and extension of our knowledge of these forms.

Lloyd, L. T. 1921. The biology of North American caddis fly larvæ. Bulletin of the Lloyd Library of Botany, Pharmacy and Materia Medica. No. 21, pp. 1-124. 

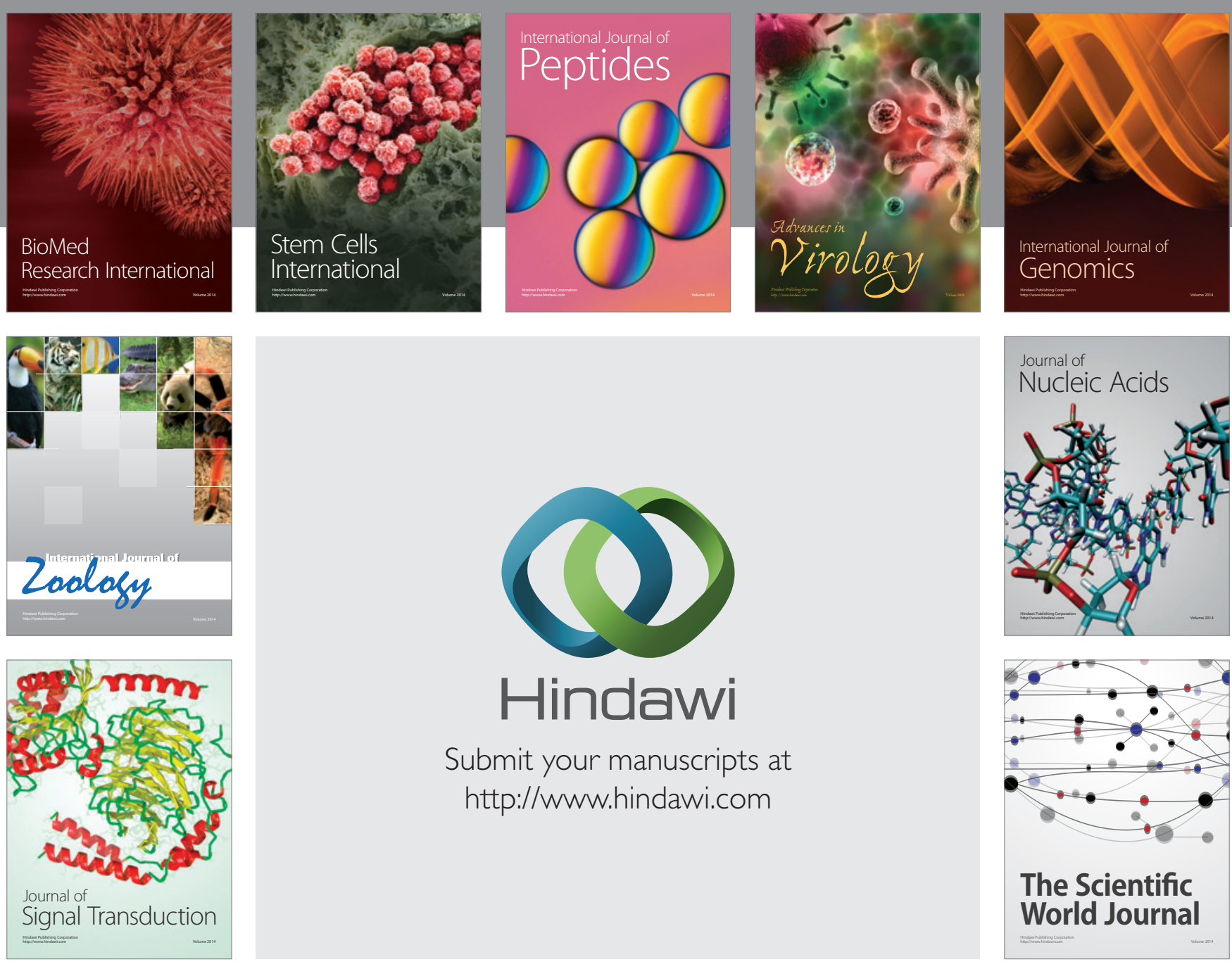

Submit your manuscripts at

http://www.hindawi.com
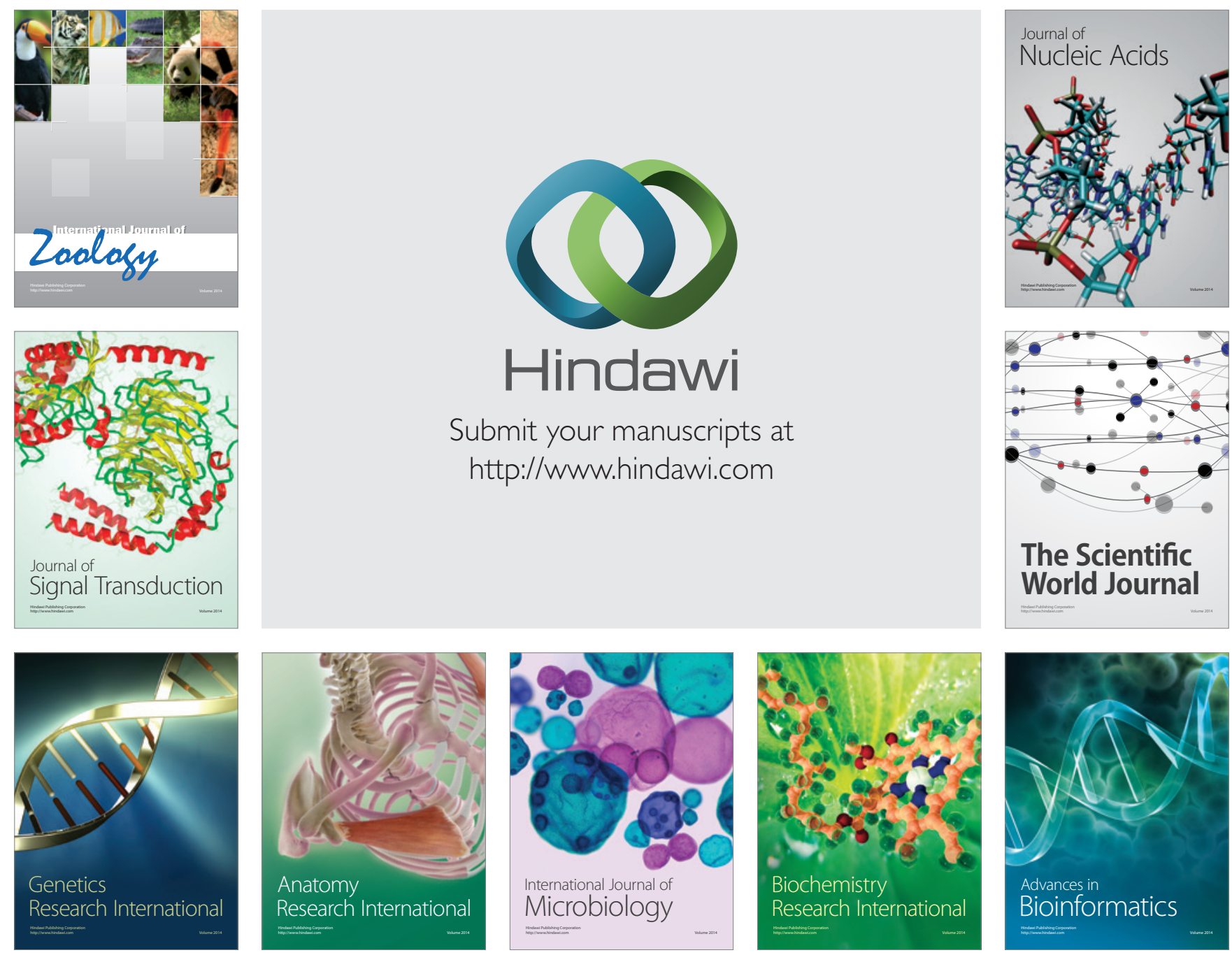

The Scientific World Journal
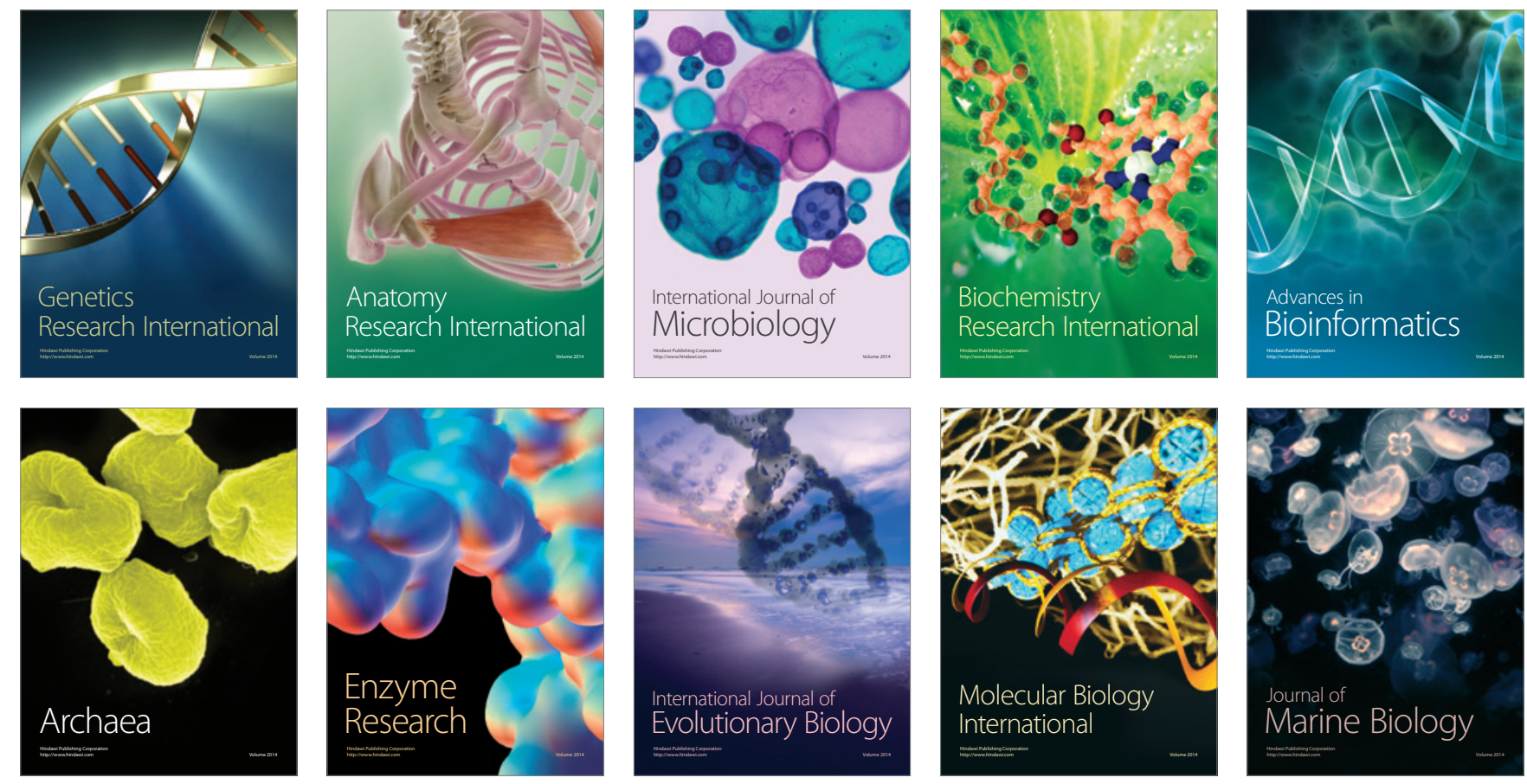